\title{
The Quantity and Quality of Teachers: A Dynamic Trade-off
}

\author{
GREGORY GILPIN \\ MiCHAEL KAGANOVICH
}

\begin{abstract}
CESIFO WORKING PAPER NO. 2516
CATEGORY 5: Fiscal Policy, MACROECONOMICS AND GROWTH
\end{abstract} JANUARY 2009

\footnotetext{
An electronic version of the paper may be downloaded

- from the SSRN website: www.SSRN.com

- from the RePEc website: - from the CESifo website: 


\title{
The Quantity and Quality of Teachers: A Dynamic Trade-off
}

\begin{abstract}
We study the dynamics of the quantity and quality of teachers in the framework of dynamic general equilibrium OLG model. The quantity and quality are jointly set by a government agency wishing to maximize the quality of basic education per student while being bound by teachers' collective bargaining agreement which equalizes teacher pay. Our model features two stages of education: basic and advanced (college), the latter being required of teachers. The cost of hiring teachers is influenced by the outside opportunities that college educated individuals have in the production sector. We show that this factor strengthens in the process of endogenous growth and moreover that it pushes the optimal trade-off between quantity and quality of teachers in the direction of the former. Namely, the number of teachers hired will grow over time while their relative quality (but not the absolute human capital attainment) will fall. This evolution of human capital accumulation is accompanied by increasing inequality, within the group of college educated workers in particular. Further, we consider the comparative dynamics effect of an exogenous skill biased technological change represented by a positive shock to productivity of the skilled workers, hence to the college premium. We show that this will exacerbate the negative trends in the quality of basic education in relation to GDP growth. Countering this trend would therefore require an increase in the share of GDP spent on basic education, assuming that the institutional setup of the school system remains unchanged.
\end{abstract}

JEL Code: H52, I2, O4.

Keywords: basic and college education, skill premium, student-teacher ratio.

\author{
Gregory Gilpin \\ Department of Economics \\ Indiana University \\ Wylie Hall \\ Bloomington, IN, 47405 \\ USA \\ gagilpin@indiana.edu
}

\author{
Michael Kaganovich \\ Department of Economics \\ Indiana University \\ Wylie Hall \\ Bloomington, IN, 47405 \\ USA \\ mkaganov@indiana.edu
}




\section{Introduction}

Increasing focus on "individual based instruction" continues to be one of the main education policy priorities in the United States as a means to raising education quality. This is evidenced by the dynamics of student-teacher ratio which has fallen from 25.8 in 1960 to 15.9 in 2003 (Digest for Education Statistics 2004, table 63). Research, however, has shown that students' test scores have not risen despite increased individualized instruction. This discrepancy has compelled policy makers and researchers to question the factors affecting students' test scores and the role of the quality of teachers vs. their quantity (see Hanushek et al (2005)). This paper develops a theoretical framework for analyzing this quantity-quality trade-off and offers an explanation to the observed trend biased in favor of quantity.

Some of the changes in school inputs and students' test scores between 1955 and 2003 are displayed in Table 1. It shows that the decline in the student-teacher ratio was accompanied by declining relative teacher salaries while the overall K-12 public education expenditures have been increasing by roughly $1 \%$ of GDP per decade.

\begin{tabular}{|c|c|c|c|c|c|}
\hline Year & Enrollment ${ }^{1, a}$ & Teachers ${ }^{1, a}$ & $\begin{array}{c}\text { Pupil / teacher } \\
\text { ratio }\end{array}$ & $\begin{array}{l}\text { Expenditures to } \\
\mathrm{GDP}^{2, \mathrm{~b}}\end{array}$ & $\begin{array}{c}\text { Relative Teacher } \\
\text { Salary }\end{array}$ \\
\hline 1955 & 30,680 & 1,141 & 26.9 & $3.3^{c}$ & \\
\hline 1960 & 36,281 & 1,408 & 25.8 & 3.6 & 43 \\
\hline 1965 & 42,173 & 1,710 & 24.7 & 3.9 & \\
\hline 1970 & 45,894 & 2,059 & 22.3 & 4.6 & 44 \\
\hline 1975 & 44,819 & 2,198 & 20.4 & 4.6 & \\
\hline 1980 & 40,877 & 2,184 & 18.7 & 4.0 & 41 \\
\hline 1985 & 39,422 & 2,206 & 17.9 & 3.8 & \\
\hline 1990 & 41,217 & 2,398 & 17.2 & 4.3 & 35 \\
\hline 1995 & 44,840 & 2,598 & 17.3 & 4.3 & \\
\hline 2000 & 47,204 & 2,941 & 16.0 & 4.5 & 36.5 \\
\hline 2005 & 49,113 & 3,137 & 15.7 & 4.6 & \\
\hline $\begin{array}{l}\text { Source: } \\
\text { 1: Digest fo } \\
\text { 2: Digest fo } \\
\text { 3: Hanushek }\end{array}$ & $\begin{array}{l}\text { or Education } \\
\text { or Education } \\
\text { \& Rivkin (20) }\end{array}$ & $\begin{array}{l}\text { Statistics } 2004 \\
\text { Statistics } 2004 \\
03 \text { ) }\end{array}$ & $\begin{array}{l}\text { Table } 61 \\
\text { Aable } 25\end{array}$ & \multicolumn{2}{|c|}{$\begin{array}{l}\text { Notes: } \\
\text { a: In thousands } \\
\text { b: In Percent } \\
\text { c: } 1959 \text { data } \\
\text { d: College educated females, age } 20- \\
\text { 29, earning less than average } \\
\text { female teacher, age } 20-29\end{array}$} \\
\hline
\end{tabular}

Another significant effect from changing education policy is the decline in the aptitude of teachers relative to educated workers. Hoxby and Andrews (2004) estimate that in $196341 \%$ of 
all teachers were of the "middle" aptitude relative to their educated peers, with $17 \%$ above and $42 \%$ below the average; in comparison, in $2000,28 \%$ of all teachers were of the "middle" aptitude with 5\% above and 67\% below average. Corcoran et al (2002) provide similar results. Interestingly, student test scores have remained roughly constant despite the substantial growth in public education outlays. In the literature, much attention has focused on explaining how these different inputs in K-12 public school system have affected students' test scores.

Many of the conflicting conclusions in the literature concerning the factors affecting student performance boil down to two general empirical strategies in the literature used to estimate the returns to quality and quantity of teachers. The first strategy attempts to estimate which teacher characteristics affect student achievement while partially controlling class size (see Aaronson (2007), Clotfelter (2007), Rivkin et al (2005), Goldhaber and Anthony (2007)). Class size is naturally constrained due to geographic and time proximities of the observations (teachers in the same state are under one mandated student-teacher ratio). The second empirical strategy aims to estimate how class size affects student achievement while attempting to control for teacher quality. Several studies which follow this strategy use data from policy experiments producing random assignment of students to smaller and larger classes. Then controlling for teacher quality this data yields unbiased estimates of the effects of class size on student achievement (see Angrist and Lavy (1999), Krueger and Whitmore, 2001, Krueger (1999), Jepsen and Rivkin (2002)).

Using data from North Carolina, Clotfelter et al (2007) conclude that teacher experience, test scores and regular licensure all have greater positive effects on student achievement, whether compared to the effects of changes in class size or to the socioeconomic characteristics of students. Aaronson et al (2007) use the data on Chicago public high school students and teachers at the classroom level to estimate how teacher characteristics affect mathematics test scores. They find that replacing a teacher with another that is rated two standard deviations superior in quality can add 0.35 to 0.45 grade equivalents, or 30 to 40 percent of an average school year's worth, to a student's math score performance. Goldhaber and Anthony (2007) also use the same North Carolina data to examine the effects of the National Board Certification process and find mixed evidence that improved observable teacher credentials have positive impact on student achievement. These results are similar to Rivkin et al (2005) who use the UTD Texas Schools Project. On the other hand, Angrist and Lavy (1999) use Israel's class size maximum to estimate 
class size effects on student achievement. They find that reducing class size causes significant and substantial increase in test scores for fourth and fifth graders, although not for third graders. Krueger (1999) analyzes data from Tennessee Project STAR to estimate the effects of class size reductions on student performance on standardized tests. His results indicate that students' scores increase by four percentage points in the first year students attend smaller classes while in subsequent years the test scores grow by about one percentage point per year. Hanushek (1999) rebuts Krueger's findings citing important design and implementation issues from the STAR project that suggest the returns to class size reduction are biased upwards. Krueger and Whitmore (2001) follow up on students who participated in the Tennessee STAR experiment and find that they had, on average, ACT scores of .13 standard deviations higher.

Another approach is to use longitudinal data on declining class size. Card and Krueger (1992) find that a decrease in the pupil-teacher ratio from 30 to 25 is associated with a 0.4 percentage point increase in the rate of return to education. Hoxby (2000), however, estimates that there is no effect from decreased class size on student achievement. These opposing estimates are addressed by Jepson and Rivkin (2002). They argue that using mandated class size reduction programs as natural experiments for estimating the class size effect is problematic when these changes involve a trade-off between the quantity and quality of teachers, and that the same problem arises when time series data is used without the account for this endogenous tradeoff. Specifically, their results indicate that California's class size reduction program came at a cost of hiring lower quality teachers to staff additional classrooms which offset the benefits of smaller classes. Similarly, Hoxby (1996) also finds that school inputs can increase without gains to student achievement due to teachers' unions reducing productivity enough to offset gains from lowered class sizes.

Thus, despite a significant attention in the literature, the questions about the determinants of education quality remain open. This underscores the need for a broader theoretical framework, which would capture the dynamic interaction between different inputs in education as it is influenced by labor market in the production economy. We note in this regard a branch of recent literature which has studied how outside job market opportunities have affected the quality of teachers. Flyer and Rosen (1997) report that the three-fold increase in direct costs of education per student is attributable to the growing market opportunities for women. Hanushek and Rivkin (1997) document the decline in the earnings of women teachers relative to women in other 
occupations and suggest that the expansion of alternative opportunities reduced teacher quality. Hanushek and Rivkin (2003) estimate that in 1955, 50\% of all educated male workers earned less than male teachers, compared to $36 \%$ in 2000 . Likewise, in $1955,48 \%$ of all educated female workers earned less than female teachers compared to $29 \%$ in 2000 . Similar analyses concerning the effect of the outside work opportunities on teacher quality are proposed in Goldhaber and Liu (2003), and Bacolad (2006). Lakdawalla (2006) demonstrates that a rising skill premium of educated workers due to faster technical change, coupled with low productivity growth of skilled teachers, has lead to lower teacher quality. The mechanism he highlights is the substitution of unskilled teachers for increasingly expensive skilled teachers.

In this paper we present a theoretical model which incorporates some of the factors of education quality discussed above, in a dynamic general equilibrium framework where government education policy decisions affect and are affected by individual education and employment decisions, whereas the dynamics of human capital accumulation and labor productivity has a feedback effect on both. In our model, the government agency wishes to maximize the quality of basic education per student and faces a trade-off between the quality and quantity of teachers to be hired. Furthermore, we assume that the agency is bound by teachers' collective bargaining agreement which equalizes teacher pay. It is, indeed, well documented that teachers' unions significantly contribute to the wage compression phenomenon. Unions provide tenure to teachers and tie their salary primarily to experience rather than performance. Administrators wishing to hire higher quality teachers are forced by the unions to then provide matching raises to teachers across the board. ${ }^{1}$ Furthermore, the wage uniformity in public schools imposes similar wage rigidity on the private school teacher market (Lakdawalla, 2006).

In our model, a government education agency has two policy variables: teacher salary, which is uniform according to the collective bargaining regime, and the number of teachers to be

\footnotetext{
${ }^{1}$ It should be noted that unionization is not the sole explanation for the compression of teacher salaries. It is also due in part to the difficulty of measuring teacher productivity, especially in terms of educational value added given unobservable student characteristics. But even if such characteristics were observable, there still exists the challenge of determining criteria for performance based pay for teachers. For example, low ability students exhibit relatively low average gains in learning throughout the year, therefore an approach based on marginal improvement of students' performance would not fairly compensate teachers for working with lower ability children.
} 
hired. The model features two stages of education: basic and advanced (college), the latter being required of teachers. College graduates can also take jobs in the skilled labor force of the production sector and get paid a competitive wage according to their human capital attainment. This opportunity cost implies that the level of teacher salary set by the government agency will determine the top quality (human capital level) of a teacher who can be hired at this salary. All college graduates whose human capital is below this level will be motivated to take a teaching job at the same salary. Therefore the number of teachers the government decides to hire along with the aforementioned top quality cut-off will determine the lowest human capital cut-off among teachers. Thus the total cost of hiring teachers is affected in our model by the outside opportunities available to skilled individuals in the production sector. We show, moreover, that in the process of endogenous growth this effect strengthens and that it pushes the optimal tradeoff between quantity and quality of teachers in the direction of the former. Namely, in the face of rising (over time) cost of highly able skilled workers the government agency will find it optimal to opt for increasing the number of teachers hired while reducing the overall relative quality of the pool of teachers. (The absolute human capital attainment of teachers, however, does rise along with the overall human capital accumulation, while sliding toward the lower tail of the distribution of college educated population.) Furthermore, we show that this human capital dynamics is characterized by increasing inequality within the group of college educated workers as well as between it and the unskilled.

Thus this paper offers a theory explaining the trend in education policy in favor of lower student-teacher ratios (i.e., higher quantity of teachers) combined arguably with deteriorating teacher quality, despite growing per student schooling expenditures. We then build on these results to further analyze the impact of exogenous technological change biased toward skill, i.e. augmenting productivity of skilled workers and thereby the college premium. We show that this will exacerbate the negative trends in the quality of basic education in relation to GDP growth. Specifically, the comparative dynamics effect (relative to the benchmark trajectory) will be detrimental to the aggregate quality of teachers as well as to the quality of basic education, due to the upward shocks to the cost of skilled labor.

The paper is organized as follows. Section 2 develops a dynamic general equilibrium model with unionized public schools. Section 3 defines a competitive equilibrium, Section 4 derives main results, and Section 5 concludes. Appendix 1 contains some of the more technical 
the proofs. Appendix 2 contains a glossary of notation.

\section{The Model}

We develop a general equilibrium growth model of an economy populated by overlapping generations of individuals whose life consists of three periods: childhood, young adulthood, and old age. We identify a generation with the period when its members are young adults, thus the individuals born in period $t-1$ form a generation $G_{t}$. We assume that population size is constant in each generation $G_{t}$ and that it forms a continuum on the interval $[0,1]$. Let $\mu($.$) be the$ induced Lebesgue measure on the set of generation $G_{t}$ individuals $[0,1]$, so that $\mu([0,1])=1$ for all $t$.

Children make no decisions of their own and receive basic (or first stage) education which is provided publicly. Young adults are endowed with a unit of time and face an option of devoting a fixed fraction $n$ of it to acquiring higher education (which we will also refer to as college or second stage education); the balance of time not spent on education is inelastically devoted to work. Specifically, the individuals without college education will work for the full unit of time in the "unskilled" production workforce. Those with college education either work for the remaining fraction of time $1-n$ in the "skilled" production workforce or, if qualified by the government, can work as public school teachers. Individuals derive income from work. They spend part of it on consumption when young and invest the rest to use the returns to finance their consumption in retirement, the last period of life.

\subsection{Production}

The production sector of the economy consists of private perfectly competitive firms producing a homogeneous capital/consumption good by means of a constant returns technology which uses three factors of production - physical capital as well as unskilled and skilled human capital. The aggregate production function is given by

$$
Y_{t}=D K_{t}^{\alpha}\left[H_{t}^{u}+\theta_{t} H_{t}^{s y}\right]^{1-\alpha}
$$

where $\alpha \in[0,1], D>0$, while $K_{t}, H_{t}^{u}, H_{t}^{s y}$ stand, respectively, for aggregate supply of physical capital, unskilled human capital, and skilled human capital employed in the production sector in 
period $t$. The coefficient $\theta_{t}$ characterizes the net productivity augmentation of skilled human capital (adjusted for the shorter employment duration dues to the time spent in college) which is imbedded in technology. The sequence of $\left\{\theta_{t}\right\}_{t=o}^{\infty}$ characterizing the evolution of the skill premium in the process of technological change is assumed to be exogenously given. ${ }^{2}$

\subsection{Households}

All individuals $\omega$ of generation $G_{t}, t=0,1,2, \ldots$ have identical intertemporal preferences over consumption as young adults and retirees given by

$$
\ln c_{t, t}(\omega)+\beta \ln c_{t, t+1}(\omega)
$$

subject to the life-time budget constraint

$$
c_{t, t}(\omega)+\left(1+r_{t+1}\right)^{-1} c_{t, t+1}(\omega) \leq\left(1-\tau_{t}\right) I_{t}(\omega)
$$

where $r_{t+1}$ is the market interest rate, $I_{t}(\omega)$ is the individual's wage income which is derived from human capital, while $\tau_{t}$ is the uniform rate of labor income tax collected by the government. According to the production function (1) individuals working in the production economy receive the wage at competitive rates $w_{t}$ and $\theta_{t} w_{t}$, respectively, per unit of their unskilled or skilled human capital, whichever applies. Thus the income of individual $\omega$ who receives only basic education and attains the level of unskilled human capital $h_{t}^{u}(\omega)$ will be

$$
I_{t}^{u}(\omega)=w_{t} h_{t}^{u}(\omega)
$$

The individual $\omega$ who obtains college education, attains the level of skilled human capital $h_{t}^{s}(\omega)$ and is employed in the production sector will receive income

$$
I_{t}^{s y}(\omega)=\theta_{t} w_{t} h_{t}^{s}(\omega)
$$

College educated individuals who become teachers will receive income $I_{t}^{h}$ to be specified later.

\subsection{Human Capital Formation}

The human capital received by each child $\omega$ of generation $G_{t}$ at the first (basic) stage of his education is produced in period $t-1$ by combining children's random innate ability with public

\footnotetext{
${ }^{2}$ See Appendix 2 for the glossary of notation.
} 
education, $E_{t-1}$, according to

$$
h_{t}^{u}(\omega)=C a(\omega) E_{t-1}
$$

where $C$ is a positive constant, $E_{t-1}$ is a uniform quality of public schooling received by each child in period $t-1$ while $a(\omega)$ is the child's innate ability. We assume that innate ability is distributed independently and identically in each generation (the time indexation is thus omitted); specifically the distribution is uniform on the interval $[a, A]$. To simplify the exposition (but at no cost to the substance of the matter) we will later let $a=0$.

We will now introduce the human capital production function for the advanced (college) stage of education. Consistent with Ben-Porath (1967) and Rosen (1976) we assume that the gains from college education depend on one's prior preparation, which in turn depends on innate ability. Moreover, we assume that college education has a pre-requisite human capital threshold $h^{*}$. Rather than an ad hoc admission requirement (we assume that all individuals are free to choose to go to college but base this decision purely on income considerations) we view this threshold as a set of benchmark skills, such as adequate language and mathematical proficiency whose deficit would preclude any benefit from learning at an advanced stage. ${ }^{3}$ Specifically, we postulate that if an individual $\omega$ of generation $G_{t}$ chooses to go to college, he will become a "skilled" agent with the level of human capital given by

$$
h_{t}^{s}(\omega)=b h_{t}^{u}(\omega)+B\left[h_{t}^{u}(\omega)-h^{*}\right]
$$

where $b \in(0,1)$ and $B>0$ are given constants. Thus according to the expression (7) the gains from college education depend on the extent to which the individual's pre-college human capital attainment $h_{t}^{u}(\omega)$ exceeds the threshold $h^{*}$.

The college education production function (7) also reflects a partial loss of pre-college human capital, according to the coefficient $b$, for the purposes of skilled human capital. While

${ }^{3}$ See Su (2004) for a similar approach to college eligibility. One can envision that this knowledge threshold may evolve over time with changes in learning technology. For example, it now tends to incorporate computer literacy; while applicants are not tested on it for admission decisions, their progress in many college specialties will critically depend on it. For the purposes of our analysis $h^{*}$ is assumed fixed. Note the important distinction between this knowledge threshold, which determines a student's true performance, from the concept of an ad hoc admission threshold addressed in the "educational standards" literature, such as Betts (1998), i.e. an education policy variable that serves as a sorting device and employability signal. 
this loss is counteracted by the net productivity augmentation $\theta_{t}$ of skilled human capital according to the economy's production function (1), we impose a condition

$$
b \theta_{t}<1
$$

which indeed implies that individuals whose pre-college human capital $h_{t}^{u}(\omega)$ is at or only slightly above the threshold $h^{*}$ will not gain from attending college and therefore will not choose to do so. It is likewise logical to assume that highly able individuals, particularly those with the highest ability level A, will benefit from attending college. According to equations (6) and (7) this will be true in generation $G_{t}$ iff the following inequality holds:

$$
(b+B) C A E_{t-1} \geq B h^{*}
$$

In Section 4 we will state specific parametric assumptions which in particular ensure that the above inequality does hold at all times.

According to the expressions (6) and (7) human capital of each type, and therefore the corresponding income is an increasing function of the innate ability. Therefore if a certain individual decides to attend college then all agents with higher ability will also do so. Thus in each period $t$ there is an ability cut-off level $a_{t}^{*}$ such that an individual $\omega$ in generation $t$ will choose to attend college if and only if his ability $a(\omega)$ exceeds $a_{t}^{*}$. (Without loss of generality we'll make a convention that individuals with ability level on the threshold do choose to go to college.)

Furthermore, we will later show that the college attendance ability cut-off level is given by the formula

$$
a_{t}^{*}=\frac{1}{C E_{t-1}} \frac{\theta_{t} B h^{*}}{\theta_{t}(b+B)-1}
$$

which has a straightforward meaning: an individual will choose to attend college if and only if his resulting skilled human capital given by formula (7) adjusted for the net productivity augmentation $\theta_{t}$ will exceed his unskilled human capital derived from the first stage of education according to its production function (6).

The non-linear form of the college human capital production function (7), combined with pre-college preparation given by (6), implies that individual's advanced human capital attainment exhibits increasing returns to ability, for which the quality of basic publicly provided 
education is a complementary input. This allows us to capture an important and arguably realistic property of "ability premium" of higher education: the skill upgrade that college education provides a highly able student is disproportionately larger than the one gained by a less able peer; furthermore, while higher quality of public basic education "lifts all boats", more able students will derive disproportionately greater benefits from it. This "ability premium" argument is used in some of recent literature to explain the evidence of increasing dispersion of earnings. For example, Huggett et al. (2006) use a life-cycle framework with a multi-stage Ben-Porath type model of human capital accumulation, which exhibits increasing returns to ability at higher stages of education, to explain the evolution of wage dispersion in the U.S. Another strand of models represented by Galor and Zeira (1993) is able to explain intergenerational persistence of inequality by the presence of credit constraints. The underlying mechanism, however, is fundamentally similar: the consequence of the borrowing constraints is that investment in education exhibits increasing returns to agents' endowments (within a certain range). ${ }^{4}$ Restuccia and Urrutia (2004) use a calibrated model which includes explicit early and college stages of education to apportion the factors, including individual ability and borrowing constraints, responsible for the intergenerational persistence of income inequality. By contrast, in most models of public education, such as by Glomm and Ravikumar (1992), human capital accumulation exhibits decreasing returns to private inputs, which leads to vanishing relative variation of income.

\subsection{Quality of Basic Education}

We shall now introduce the per student basic education quality $E_{t}$, i.e. the public input in the basic education production function (6) provided in period $t$, as a function of the quality and quantity of teachers chosen by a government agency. Recall that only college educated individuals are eligible to be employed as teachers. Let $\Sigma_{t}$ be the set of individuals $\omega$ in generation $t$ employed as teachers. Let $z_{t}$ be the total number of teachers. Since population size was normalized to 1 in all generations, $z_{t}$ is also the fraction of teachers in the overall population

\footnotetext{
${ }^{4}$ Heckman and Cunha (2007) and related recent work appear to provide a unified framework for these approaches.
} 
in generation $t$, as well as the student-teacher ratio for generation $t+1$ students. We define the aggregate teacher quality as the aggregate human capital of teachers

$$
q_{t}=\int_{\omega \in \Sigma_{t}} h_{t}^{s}(\omega) d \mu_{t}(\omega)
$$

Likewise, the average teacher quality is given by $z_{t}^{-1} \int_{\omega \in \Sigma_{t}} h_{t}^{s}(\omega) d \mu_{t}(\omega)=z_{t}^{-1} q_{t}$. The explicit account for the heterogeneity of teachers' human capital attainment is obviously an essential element of our model. Earlier papers, such as by Eckstein and Zilcha (1994), which explicitly modeled teacher human capital as an input in (compulsory) schooling, assumed that it equals to the average human capital of their generation. ${ }^{5}$

We now define the quality of basic education as a Cobb-Douglas function of the quantity and aggregate quality of teachers:

$$
E_{t}=z_{t}^{\gamma} q_{t}^{v}
$$

Note that this formula corresponds to the one used by Tamura (2001) who assumed in particular that the role of personal instruction, i.e. that of teacher-student ratio, is more important for schooling effectiveness that the average quality of teachers, which in our formulation means that $\gamma \geq v$.

The special case of (10), when $\gamma=v=1$, i.e.

$$
E_{t}=z_{t} \int_{\omega \in \Sigma_{t}} h_{t}^{s}(\omega) d \mu_{t}(\omega)
$$

has a particularly straightforward interpretation. Assume that all teachers are perfectly sorted across classes, each class of equal size $z_{t}^{-1}$, so that each student through his classes is exposed to a cross-section of teachers which perfectly represents their distribution of quality. Then the expression (11) which is equivalent to $E_{t}=\int_{\omega \in \Sigma_{t}} \frac{h_{t}^{s}(\omega)}{z_{t}^{-1}} d \mu_{t}(\omega)$ can be interpreted as per student average teacher quality.

\footnotetext{
${ }^{5}$ Hatzor (2008) contrasts such regime where teachers are selected at random from the population with the one where the quality of teachers is determined endogenously with an optimal trade-off against their quantity. She focuses on comparing the implications of these regimes for growth and welfare in the framework of strategic interaction between education and budgeting authorities of the government.
} 


\subsection{Government}

The government funds and administers public education at the basic level with the goal of maximizing its quality $E_{t}$, as defined above, subject to the budget constraint given by the revenue from a uniform labor income tax at a flat rate $\tau_{t}$. To these ends in each period $t$, the government must set teachers' salary $I_{t}^{h}$ and the number of teachers to be hired $z_{t}$. As discussed in the introduction, we postulate that the salary $I_{t}^{h}$ received by all teachers in generational cohort $t$ is uniform, according to a collective bargaining agreement. Since a college educated individual has an option to work in the production sector for a competitive wage as defined by the expression (6), the government's choice of teacher salary $I_{t}^{h}$ will uniquely determine the highest level of human capital attainment $\bar{h}_{t}$ among individuals who will choose to become teachers. Indeed it should satisfy the equation 6

$$
\theta_{t} w_{t} \bar{h}_{t}=I_{t}^{h}
$$

Thus all college graduates with human capital level $h_{t}^{s}(\omega)$ at or below $\bar{h}_{t}$ will be obviously motivated to accept employment as a teacher rather than work in the production sector. However, the government's goal to maximize the overall education quality for a set number of teachers $z_{t}$ implies that the set $\Sigma_{t}$ of teachers the government will hire consists of all individuals whose level of human capital attained in college falls into the interval: $h_{t}^{s}(\omega) \in\left[\underline{h}_{t}, \bar{h}_{t}\right]$, where the minimum teacher qualification threshold $\underline{h}_{t}$ is determined by the intended number of teachers, i.e. the measure

$$
z_{t}=\mu\left(\omega \mid \underline{h}_{t} \leq h_{t}^{s}(\omega) \leq \bar{h}_{t}\right)
$$

where the top cut-off $\bar{h}_{t}$ is determined, according to (12), by the teacher salary $I_{t}^{h}$ set by the government.

\footnotetext{
${ }^{6}$ Since one's work career is summarily represented in our model by one time period, we do not model the wage dynamics over the course of a worker's or teacher's career as he accumulates seniority and experience. The appropriate understanding of the income variables in this framework is that they represent aggregates over the entire career, such as respective present values at the career's outset. While teachers' union collective bargaining agreements stipulate wage differentials based on seniority, equation (12) should be understood as the comparison of respective aggregates over the course of the alternative careers in question.
} 
Recalling the production functions of basic and advanced education given, respectively, by the expressions (6) and (7), we define the cut-off innate ability levels $\underline{a}_{t}$ and $\bar{a}_{t}$ which characterize the teachers who possess, respectively, the cut-off levels of human capital $\underline{h}_{t}$ and $\bar{h}_{t}$ induced by the government policy choice. In other words,

$$
\underline{a}_{t}=\frac{\underline{h}_{t}+B h^{*}}{(b+B) C E_{t-1}} \quad \text { and } \quad \bar{a}_{t}=\frac{\bar{h}_{t}+B h^{*}}{(b+B) C E_{t-1}}
$$

For the government policy choice of $I_{t}^{h}, z_{t}$, to be feasible, the minimum teacher qualification threshold $\underline{h}_{t}$ defined by (13) obviously must belong the range of human capital levels attained by college graduates. In other words, the corresponding ability level $\underline{a}_{t}$ must exceed the college attendance cut-off level $a_{t}^{*}$.

Thus according to (10) the government's basic education quality optimization problem can be restated as

$$
\begin{aligned}
& \max _{z_{t}, h_{t}} E_{t} \\
& \text { subject to (13) } \\
& z_{t} \theta_{t} w_{t} \bar{h}_{t}=T_{t} \text { and } \\
& \underline{a}_{t} \geq a_{t}^{*}
\end{aligned}
$$

where $T_{t}$ is the tax revenue collected by the government in period $t$.

Thanks to our assumption of the uniform distribution of innate ability on the interval $[a, A]$ and due to the linearity of basic and advanced education production functions (6) and (7) we can simplify expressions (10) and (13), respectively, as

$$
\begin{gathered}
E_{t}=z_{t}^{\gamma} q_{t}^{v}=\frac{z_{t}^{\gamma}\left[\bar{h}_{t}^{2}-\underline{h}_{t}^{2}\right]^{v}}{\left[2(A-a)(b+B) C E_{t-1}\right]^{v}} \\
z_{t}=\frac{\bar{h}_{t}-\underline{h}_{t}}{(A-a)(b+B) C E_{t-1}}
\end{gathered}
$$

and therefore problem (15) to maximize the quality of basic education $E_{t}$ subject to the government budget constraint can be restated as 


$$
\begin{aligned}
& \max _{z_{t}, \bar{h}_{t}} \frac{z_{t}^{\gamma}\left[\bar{h}_{t}^{2}-\underline{h}_{t}^{2}\right]^{v}}{\left[2(A-a)(b+B) C E_{t-1}\right]^{v}} \\
& \text { subject to (17), } \\
& z_{t} \theta_{t} w_{t} \bar{h}_{t}=T_{t} \text { and } \\
& \underline{a}_{t} \geq a_{t}^{*}
\end{aligned}
$$

or equivalently, according to (17), as

$$
\begin{aligned}
& \max _{z_{t}, h_{t}} 2^{-v}\left(\bar{h}_{t}+\underline{h}_{t}\right)^{v} z_{t}^{\gamma+v} \\
& \text { subject to (17), } \\
& z_{t} \theta_{t} w_{t} \bar{h}_{t}=T_{t} \text { and } \\
& \underline{a}_{t} \geq a_{t}^{*}
\end{aligned}
$$

Note that the optimal minimum and maximum cut-off levels of teachers' human capital are related through the optimal choice of their number $z_{t}$ according to equation (17). The optimization in problem (18) thus expresses the trade-off between the quantity and quality of teachers to be hired. The quality of the top teacher $\bar{h}_{t}$ will not only determine his salary $I_{t}^{h}=\theta_{t} w_{t} \bar{h}_{t}$ due to his outside option as a skilled worker, but also set the identical salary for all other teachers according to the equal pay-based collective bargaining agreement. (Conversely, teacher salary $I_{t}^{h}$ set by the government will uniquely determine the top teacher quality $\bar{h}_{t}$.) Hence the total teachers' wage bill $z_{t} \theta_{t} w_{t} \bar{h}_{t}$ in the government's budget constraint.

According to the relationships (14), the expression (17) is equivalent to

$$
z_{t}=\frac{\bar{a}_{t}-\underline{a}_{t}}{A-a}
$$

Therefore using relationships (14) to express $\bar{h}_{t}$ and $\underline{h}_{t}$ and then eliminate $\underline{a}_{t}$ according to formula (19), we obtain

$$
q_{t}=\frac{\bar{h}_{t}^{2}-\underline{h}_{t}^{2}}{2(A-a)(b+B) C E_{t-1}}=\left[(b+B) C E_{t-1} \bar{a}_{t}-B h^{*}-\frac{1}{2} z_{t}(A-a)(b+B) C E_{t-1}\right] z_{t}
$$


so we can restate the government's education quality optimization problem (18) as

$$
\begin{aligned}
& \max _{z_{t}, \bar{a}_{t}} E_{t}=2^{-v}\left[2(b+B) C E_{t-1} \bar{a}_{t}-2 B h^{*}-z_{t}(A-a)(b+B) C E_{t-1}\right]^{v} z_{t}^{\gamma+v} \\
& \text { subject to } z_{t} \theta_{t} w_{t}\left[(b+B) C E_{t-1} \bar{a}_{t}-B h^{*}\right]=T_{t} \text { and } \\
& \bar{a}_{t}-z_{t}(A-a) \geq a_{t}^{*}
\end{aligned}
$$

\section{General Equilibrium and Optimal Policy}

We can now summarize the fundamental elements of the model and their relationships in a general equilibrium framework. We will first define the dynamic general equilibrium for a given government policy parameters and then explore the government's optimal determination of the quality of basic education.

Given the sequence of tax rates $\left\{\tau_{t}\right\}_{t=0}^{\infty}$ and the sequence of government education policy parameters $\left\{I_{t}^{h}, z_{t}\right\}_{t=0}^{\infty}$, i.e. teacher salaries and the numbers of teachers hired in each period, respectively, as well as the initial period $t=0$ aggregate supply of capital $K_{0}$, the distributions of the retirees' consumption levels $c_{-1,0}(\omega)$, and per students basic education quality $E_{-1}$ provided to generation $G_{0}$ individuals as children, we define the dynamic general equilibrium as a collection of sequences of

(a) factor prices $\left\{\left(1+r_{t+1}\right), w_{t}, \theta_{t} w_{t}\right\}_{t=0}^{\infty}$ respectively of physical, unskilled and skilled human capital as inputs in production in period $t$;

(b) aggregate variables $\left\{Y_{t}, K_{t}, H_{t}^{u}, H_{t}^{s y}, T_{t}, E_{t}, a_{t}^{*}\right\}_{t=0}^{\infty}$, i.e., respectively, aggregate output, inputs of physical, unskilled and skilled human capital in production, government's tax revenue, the quality of basic education provided to each student in period $t$, as well as the endogenous innate ability cut-off for college attendance;

(c) distributions of individual consumption and education decisions

$\left\{c_{t, t}(\omega), c_{t, t+1}(\omega), h_{t}^{u}(\omega), h_{t}^{s}(\omega)\right\}_{t=0}^{\infty}$, as well as employment decisions by college educated individuals

such that 
(i) the factor prices are determined competitively, i.e. set equal to the marginal products of respective inputs:

$$
1+r_{t+1}=\alpha D K_{t}^{\alpha-1}\left[H_{t}^{u}+\theta_{t} H_{t}^{s y}\right]^{1-\alpha}, w_{t}=(1-\alpha) D K_{t}^{\alpha}\left[H_{t}^{u}+\theta_{t} H_{t}^{s y}\right]^{-\alpha}
$$

(ii) each individual $\omega \in[0,1]$ in generation $G_{t}$ makes a decision whether to go to college and if so whether to be employed as a teacher or in the production sector so as to maximize his income while taking as given their basic education quality $E_{t-1}$, production sector wage rates $w_{t}$ and $\theta_{t} w_{t}$ (for unskilled and skilled labor, respectively), teacher salary $I_{t}^{h}$ and the number of teachers $z_{t}$ to be hired, whereas his human capital level $h_{t}^{u}(\omega)$ or $h_{t}^{s}(\omega)$ (depending on his college attendance decision) is determined according to the education production functions (6) and (7); (note that according to equation (12) and the collective bargaining agreement a teacher's salary will exceed production sector wage for all but the top quality teacher, so the government teacher employment limit $z_{t}$ will bind;)

(iii) based on his income $I_{t}(\omega)$ determined according to (ii), each individual $\omega \in[0,1]$ in generation $G_{t}$ makes his young- and old-age consumption decisions $c_{t, t}(\omega), c_{t, t+1}(\omega)$ by solving the optimization problem (2)-(3) while taking the rates of interest $1+r_{t+1}$ and $\operatorname{tax} \tau_{t}$ as given;

(iv) the quality of basic education $E_{t}$ provided to generation $G_{t+1}$ individuals (as children) is determined by the expression (10) while the set of teachers $\Sigma_{t}$ is defined by individual employment decisions according to (ii) while the number of teachers hired $z_{t}$ is as given;

(v) the markets for goods, physical capital and both skilled and unskilled labor clears in each period:

$$
\begin{aligned}
& Y_{t}=\int_{\omega \in[0,1]} c_{t, t}(\omega) d \mu_{t}(\omega)+\int_{\omega \in[0,1]} c_{t-1, t}(\omega) d \mu_{t-1}(\omega), \\
& K_{t}=\left(1+r_{t+1}\right)^{-1} \int_{\omega \in[0,1]} c_{t, t+1}(\omega) d \mu_{t}(\omega),
\end{aligned}
$$




$$
\begin{aligned}
& H_{t}^{u}=\int_{a \leq a(\omega) \leq a_{t}^{*}} h_{t}^{u}(\omega) d \mu_{t}(\omega), \\
& H_{t}^{s y}=\int_{a_{t}^{*} \leq a(\omega) \leq A} h_{t}^{s}(\omega) d \mu_{t}(\omega)-\int_{\omega \in \Sigma_{t}} h_{t}^{s}(\omega) d \mu_{t}(\omega),
\end{aligned}
$$

where the ability cut-off for college attendance $a_{t}^{*}$ is determined by individual college attendance decisions as defined in (ii);

(vi) the aggregate tax revenue is composed of labor income taxes collected from all categories of employees, i.e.

$$
T_{t}=\tau_{t}\left(w_{t} H_{t}^{u}+\theta_{t} w_{t} H_{t}^{s y}+z_{t} I_{t}^{h}\right)
$$

We can now define the government's optimal education policy in period $t$ recursively, based on the above general equilibrium construct. Namely, the government chooses teacher salaries $I_{t}^{h}$ and the numbers of teachers $z_{t}$ for period $t$ by solving the optimization problem (18) (or, equivalently, the problem (20)) where the top teacher quality $\bar{h}_{t}$ is determined by equation (12), while taking as given the economy's general equilibrium values of production sector wage rate $w_{t}$, aggregate tax revenue $T_{t}$ and the distribution of skilled human capital attainment $h_{t}^{s}(\omega)$ by generation $G_{t}$ individuals.

Noting the mutual dependence of the general equilibrium variables in period $t$ and the government's optimal education policy we define the Education-Economy recursive dynamic equilibrium (RDE for brevity) as a fixed point of this relationship, recursively determined for each period $t$.

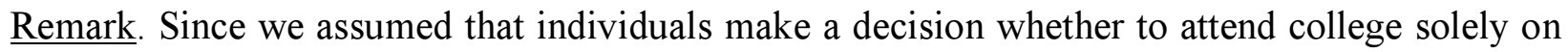
the basis of maximizing income, it is clear that the ability cut-off for college attendance $a_{t}^{*}$ defined in part (ii) of the definition of the dynamic general equilibrium, should satisfy inequality

$$
a_{t}^{*} \leq \frac{1}{C E_{t-1}} \frac{\theta_{t} B h^{*}}{\theta_{t}(b+B)-1}
$$

Indeed, according to (6), (7) and (4), (5), an individual with ability exceeding the right hand side of (26) will certainly increase his income by going to college. In fact, we will show in the next 
section that in the RDE inequality (26) is satisfied as equality, i.e. equality (9) is true.

\section{Analysis of the Model}

To reduce the unessential analytical complexity we will assume henceforth without any additional substantive loss of generality that parameter $a=0$, i.e. innate ability in each generation is distributed uniformly on the interval $[0, A]$. We begin by analyzing the government's optimal education policy problem equivalently stated as in (18) or (20).

We impose the following restrictions on the economy's parameters, where $E_{-1}$ is an exogenously given per student basic education quality provided to generation $G_{0}$ individuals.

Assumption 1. $\left(\frac{v}{\gamma}(b+B) A C\left(1-\tau_{t}\right)\right)^{\frac{1}{2+\gamma / v}}\left(\left(\frac{\gamma}{2 v+\gamma}\right)\left(\frac{\tau_{t}}{1-\tau_{t}}\right)\right)^{\frac{1+\gamma / 2 v}{2+\gamma / v}}\left(1-\frac{B h^{*}}{(b+B) A C E_{-1}}\right)>1$ is true for any $t=0,1, \ldots$

Assumption 2. $\left(\frac{v\left(1-\tau_{t}\right)}{\gamma}-\frac{1}{2}\right)\left(\left(\frac{\gamma}{2 v+\gamma}\right)\left(\frac{\tau_{t}}{1-\tau_{t}}\right)\right)^{1 / 2}\left(1-\frac{B h^{*}}{(b+B) A C E_{-1}}\right)>\frac{1}{\theta_{t}(b+B)}$ is true for any $t=0,1, \ldots$

The above assumptions require that education taxes $\tau_{t}$ not be too small while not exceeding $1-\frac{\gamma}{2 v}$, which of course imposes a requirement that $\gamma$, the relative importance of the teacher-student ratio for schooling effectiveness, should not be substantially greater than $v$, the relative importance of the teacher quality. The main thrust of the assumptions, however, concerns the parameters which characterize educational gains. Assumption 1 is satisfied if parameter $C$ characterizing the gains in basic education is sufficiently large. Assumption 2 will hold if $(b+B)$, a productivity characteristic of the college education production function, is large enough.

Based on these assumptions we will characterize the optimal solution of the education quality optimization problem in terms of the optimal number of teachers $z_{t}$ for period $t$, the corresponding range of teachers' human capital, i.e. its maximum and minimum values $\bar{h}_{t}, \underline{h}_{t}$ 
induced by the policy and the corresponding innate ability levels $\bar{a}_{t}, \underline{a}_{t}$. In the process we will establish the following important facts (see Appendix 1 for the proofs):

Lemma 1 (Growth of Basic Education Quality). The recursive equilibrium dynamics exhibits sustained growth of the quality of per student basic education. Specifically, there is a rate $g>1$ such that $E_{t}>g E_{t-1}$ is true for allt $=0,1, \ldots$

Lemma 2 (The Interiority Property). In the recursive dynamic equilibrium, the ability of the least qualified teacher exceeds the college attendance cut-off ability in all time periods, i.e. $\underline{a}_{t}>a_{t}^{*}$ is true for $t=0,1, \ldots$. Thereby the human capital of the least qualified teacher will not be the lowest among his contemporary college graduates.

Lemma 3. The ability cut-off for college attendance $a_{t}^{*}$ satisfies equality (9), i.e.

$$
a_{t}^{*}=\frac{1}{C E_{t-1}} \frac{\theta_{t} B h^{*}}{\theta_{t}(b+B)-1}
$$

which means that an individual will choose to attend college if and only if his resulting skilled human capital given by formula (7) adjusted for the net productivity augmentation $\theta_{t}$ will exceed his unskilled human capital derived from the basic stage of education according to its production function (6).

We now proceed to solving the optimization problem (20).

According to the teacher salary equation (12) and the tax revenue formula (25), the government budget constraint can be stated as

$$
\left(1-\tau_{t}\right) z_{t} \theta_{t} \bar{h}_{t}=\tau_{t}\left(H_{t}^{u}+\theta_{t} H_{t}^{s y}\right)
$$

Using the education production functions (6) and (7), and the assumption that innate ability is uniformly distributed on $[0, A]$ we can rewrite the general equilibrium relationships $(23),(24)$ as

$$
H_{t}^{u}=C E_{t-1} \int_{0}^{a_{t}^{*}} \frac{a}{A} d a=\frac{\left(a_{t}^{*}\right)^{2}}{2 A} C E_{t-1}
$$




$$
\begin{aligned}
H_{t}^{s y} & =\int_{a_{t}^{*}}^{A}\left[(b+B) C E_{t-1} a-B h^{*}\right] \frac{1}{A} d a-\int_{\underline{a}_{t}}^{\bar{a}_{t}}\left[(b+B) C E_{t-1} a-B h^{*}\right] \frac{1}{A} d a= \\
& =\frac{(b+B) C E_{t-1}}{2 A}\left[A^{2}-\left(a_{t}^{*}\right)^{2}-\left(\bar{a}_{t}\right)^{2}+\left(\underline{a}_{t}\right)^{2}\right]-\frac{B h^{*}}{A}\left[A-a_{t}^{*}-\bar{a}_{t}+\underline{a}_{t}\right]
\end{aligned}
$$

Therefore expressing $\bar{h}_{t}$ through $\bar{a}_{t}$ according to the relationship in (14) we can rewrite the budget constraint (27) as

$$
\begin{aligned}
& \left(1-\tau_{t}\right) \theta_{t} z_{t}\left((b+B) C E_{t-1} \bar{a}_{t}-B h^{*}\right)= \\
& \quad \frac{\tau_{t} C E_{t-1}}{2 A}\left[\left(a_{t}^{*}\right)^{2}+\theta_{t}(b+B)\left(A^{2}-\left(a_{t}^{*}\right)^{2}-\left(\bar{a}_{t}\right)^{2}+\left(\underline{a}_{t}\right)^{2}\right)\right]-\frac{\tau_{t} \theta_{t} B h^{*}}{A}\left[A-a_{t}^{*}-\bar{a}_{t}+\underline{a}_{t}\right]
\end{aligned}
$$

We now eliminate variables $a_{t}^{*}$ and $\underline{a}_{t}$ from (30) by substituting the value of $a_{t}^{*}$ given by (9), based on the above Lemma 3, and using the expression $\underline{a}_{t}=\bar{a}_{t}-A z_{t}$, which follows from the relationship (19) since we set $a=0$. This immediately turns expression (30) into a linear equation in terms of variable $\bar{a}_{t}$ which yields

$$
\bar{a}_{t}=\frac{z_{t} \tau_{t} A}{2}+\frac{B h^{*}}{(b+B) C E_{t-1}}+\frac{\tau_{t} A}{2 z_{t}}\left(1-\frac{2 B h^{*}}{A(b+B) C E_{t-1}}+\frac{\theta_{t}\left(B h^{*}\right)^{2}}{\left(\theta_{t}(b+B)-1\right)(b+B)\left(A C E_{t-1}\right)^{2}}\right)
$$

This expression incorporates the government budget constraint of problem (20). That problem's objective function, upon substituting the expression (31) for $\bar{a}_{t}$, becomes a function of a single variable $z_{t}$. We will solve for its unconstrained maximization and then refer to Lemma 2 which ensures that the only remaining constraint $\bar{a}_{t}-A z_{t} \geq a_{t}^{*}$ in the government optimization problem (20) is automatically fulfilled.

Thus we are looking at the unconstrained maximization of the following function:

$F\left(z_{t}\right)=q_{t}^{v} z_{t}^{\gamma}=\left(\frac{\tau_{t}(b+B) A C E_{t-1}}{2}-\tau_{t} B h^{*}+\frac{\tau_{t} \theta_{t} B^{2} h^{* 2}}{2\left(\theta_{t}(b+B)-1\right) A C E_{t-1}}-\frac{\left(1-\tau_{t}\right)(b+B) A C E_{t-1} z_{t}^{2}}{2}\right)^{v} z_{t}^{\gamma}$

Its first order necessary condition is given by the equation

$$
\gamma z_{t}^{\gamma-1} q_{t}^{\nu}-v\left(1-\tau_{t}\right)(b+B) A C E_{t-1} z_{t}^{\gamma+1} q_{t}^{\nu-1}=0
$$

yielding unique non-negative solution: 


$$
z_{t}=\left(\left(\frac{\gamma}{2 v+\gamma}\right)\left(\frac{\tau_{t}}{1-\tau_{t}}\right)\right)^{1 / 2}\left(1-\frac{2 B h^{*}}{(b+B) A C E_{t-1}}+\frac{\theta_{t}\left(B h^{*}\right)^{2}}{\left(\theta_{t}(b+B)-1\right)(b+B)\left(A C E_{t-1}\right)^{2}}\right)^{1 / 2}
$$

It is straightforward to verify that this solution also satisfies the second order sufficient condition of the maximization problem. Substituting expression (33) back into formula (31) we obtain

$$
\bar{a}_{t}=\frac{\tau \hat{a} z_{t}}{2}+\frac{B h^{*}}{(b+B) C E_{t-1}}+\frac{\tau A}{2 z_{t}}\left(1-\frac{2 B h^{*}}{(b+B) A C E_{t-1}}+\frac{\theta_{t}\left(B h^{*}\right)^{2}}{\left(\theta_{t}(b+B)-1\right)(b+B)\left(A C E_{t-1}\right)^{2}}\right)
$$

which simplifies, by using equation (33) again, into

$$
\bar{a}_{t}=\frac{\tau_{t} A z_{t}}{2}+\frac{B h^{*}}{(b+B) C E_{t-1}}+\frac{(2 v+\gamma)\left(1-\tau_{t}\right) A z_{t}}{2 \gamma}=\frac{B h^{*}}{(b+B) C E_{t-1}}+A z_{t}\left(\frac{v\left(1-\tau_{t}\right)}{\gamma}+\frac{1}{2}\right)
$$

Recall that $\underline{a}_{t}=\bar{a}_{t}-A z_{t}$ according to (19) since we set $a=0$. Applying this to (34) we obtain

$$
\underline{a}_{t}=\frac{B h^{*}}{(b+B) C E_{t-1}}+A z_{t}\left(\frac{\nu\left(1-\tau_{t}\right)}{\gamma}-\frac{1}{2}\right)
$$

Observe that the education policy optimization as well as the individuals' and the production sector's general equilibrium reactions are determined recursively. Indeed, according to expressions (33) - (35), education quality $E_{t-1}$ uniquely determines optimal education policy in period $t$, i.e. their number, as well as the range of their innate abilities and thereby due to (14) the range of their human capital attainment. This in turn will uniquely determine college attendance and employment decisions by generation $t$ individuals, hence their incomes and their allocations. Government's education policy will also determine the current period's basic education quality $E_{t}$, so the recursion continues.

Consider now the effect of the previous period's education quality $E_{t-1}$ on education decision variables in period $t$. By differentiating the expressions (9) and (33) we obtain:

$$
\begin{aligned}
& \frac{\partial a_{t}^{*}}{\partial E_{t-1}}=\frac{-\theta_{t} B h^{*}}{\left(\theta_{t}(b+B)-1\right) C E_{t-1}^{2}}<0 \\
& \frac{\partial z_{t}}{\partial E_{t-1}}=\frac{1}{z_{t}}\left(\frac{\gamma}{2 v+\gamma}\right)\left(\frac{\tau_{t}}{1-\tau_{t}}\right)\left(\frac{B h^{*}}{(b+B) A C E_{t-1}^{2}}\left(1-\frac{a_{t}^{*}}{A}\right)\right)>0
\end{aligned}
$$


According to (34) and (35), respectively, we can write

$$
\begin{aligned}
& \frac{\partial \bar{a}_{t}}{\partial E_{t-1}}=-\frac{B h^{*}}{(b+B) C E_{t-1}^{2}}+\frac{A}{z_{t}}\left(\frac{2 v\left(1-\tau_{t}\right)+\gamma}{2 \gamma}\right)\left(\frac{\gamma}{2 v+\gamma}\right)\left(\frac{\tau_{t}}{1-\tau_{t}}\right)\left(\frac{B h^{*}}{(b+B) A C E_{t-1}^{2}}\left(1-\frac{a_{t}^{*}}{A}\right)\right)= \\
& \frac{B h^{*}}{(b+B) C E_{t-1}^{2}}\left(-1+z_{t}^{-1}\left(\frac{2 v\left(1-\tau_{t}\right)+\gamma}{2 \gamma}\right)\left(\frac{\gamma}{2 \nu+\gamma}\right)\left(\frac{\tau_{t}}{1-\tau_{t}}\right)\left(1-\frac{a_{t}^{*}}{A}\right)\right) \\
& \frac{\partial \underline{a}_{t}}{\partial E_{t-1}}=-\frac{B h^{*}}{(b+B) C E_{t-1}^{2}}+A z_{t}^{-1}\left(\frac{2 v\left(1-\tau_{t}\right)-\gamma}{2 \gamma}\right)\left(\frac{\gamma}{2 v+\gamma}\right)\left(\frac{\tau_{t}}{1-\tau_{t}}\right)\left(\frac{B h^{*}}{(b+B) A C E_{t-1}^{2}}\left(1-\frac{a_{t}^{*}}{A}\right)\right)= \\
& \frac{B h^{*}}{(b+B) C E_{t-1}^{2}}\left(-1+z_{t}^{-1}\left(\frac{2 v\left(1-\tau_{t}\right)-\gamma}{2 \gamma}\right)\left(\frac{\gamma}{2 v+\gamma}\right)\left(\frac{\tau_{t}}{1-\tau_{t}}\right)\left(1-\frac{a_{t}^{*}}{A}\right)\right)
\end{aligned}
$$

Note that since $\frac{\theta_{t}(b+B)}{\theta_{t}(b+B)-1}>1$, the following inequality is true

$$
1-\frac{2 B h^{*}}{(b+B) A C E_{t-1}}+\frac{\theta_{t}\left(B h^{*}\right)^{2}}{(b+B)\left(\theta_{t}(b+B)-1\right)\left(A C E_{t-1}\right)^{2}}>\left[1-\frac{B h^{*}}{(b+B) A C E_{t-1}}\right]^{2}
$$

Therefore according to (33)

$$
\begin{aligned}
& z_{t}>\left(\left(\frac{\gamma}{2 v+\gamma}\right)\left(\frac{\tau_{t}}{1-\tau_{t}}\right)\right)^{1 / 2}\left(1-\frac{B h^{*}}{(b+B) A C E_{t-1}}\right)>\left(\left(\frac{\gamma}{2 v+\gamma}\right)\left(\frac{\tau_{t}}{1-\tau_{t}}\right)\right)^{1 / 2}\left(1-\frac{\theta_{t} B h^{*}}{\left(\theta_{t}(b+B)-1\right)\left(A C E_{t-1}\right)}\right)= \\
& =\left(\left(\frac{\gamma}{2 v+\gamma}\right)\left(\frac{\tau_{t}}{1-\tau_{t}}\right)\right)^{1 / 2}\left(1-\frac{a_{t}^{*}}{A}\right)
\end{aligned}
$$

Thus the expression (38) will be negative as long as the inequality

$$
\left(\left(\frac{\gamma}{2 \nu+\gamma}\right)\left(\frac{\tau_{t}}{1-\tau_{t}}\right)\right)^{1 / 2}>\left(\frac{\gamma}{2 \nu+\gamma}\right)\left(\frac{\tau_{t}}{1-\tau_{t}}\right)\left(\frac{2 \nu\left(1-\tau_{t}\right)+\gamma}{2 \gamma}\right)
$$

is true, which is certainly the case under the non-binding condition $\tau_{t}<\frac{4}{5+2 v / \gamma}$ on the tax rate (see Appendix 1 for the proof of this assertion). Comparing expressions (38) and (39) one can see that negativity of (38) implies the same for (39). Therefore we can conclude that

$$
\frac{\partial \bar{a}_{t}}{\partial E_{t-1}}<0, \quad \frac{\partial \underline{a}_{t}}{\partial E_{t-1}}<0
$$

Combining these facts with Lemma 1 , which shows that education quality $E_{t-1}$ does in fact grow 
over time, we obtain our central result.

Theorem 1 (Dynamics of the Quantity and Quality of Teachers). The recursive dynamic equilibrium (RDE) exhibits the following evolution of education policy variables:

- the quantity of teachers $z_{t}$ will grow over time;

- the relative quality of teachers characterized by the range of their innate abilities falls: both the upper and the lower thresholds $\bar{a}_{t}, \underline{a}_{t}$ decrease over time;

- $\quad$ the college attendance ability-cut-off $a_{t}^{*}$ also drops over time and (according to Lemma 2) remains consistently below the lower ability threshold for teachers $\underline{a}_{t}$.

Recall that according to relationships (14)

$$
\underline{h}_{t}=\underline{a}_{t}(b+B) C E_{t-1}-B h^{*} \text { and } \bar{h}_{t}=\bar{a}_{t}(b+B) C E_{t-1}-B h^{*}
$$

Therefore due to (34) and (35), respectively, as well as to (33) we can write

$$
\begin{aligned}
& \bar{h}_{t}=(b+B) A C E_{t-1}\left(\frac{v\left(1-\tau_{t}\right)}{\gamma}-\frac{1}{2}\right) z_{t} \\
& =(b+B) C A\left(\frac{v\left(1-\tau_{t}\right)}{\gamma}-\frac{1}{2}\right)\left(\left(\frac{\gamma}{2 v+\gamma}\right)\left(\frac{\tau_{t}}{1-\tau_{t}}\right)\right)^{1 / 2}\left(E_{t-1}^{2}-\frac{2 B h^{*} E_{t-1}}{(b+B) A C}+\frac{\theta_{t}\left(B h^{*}\right)^{2}}{\left(\theta_{t}(b+B)-1\right)(b+B)(A C)^{2}}\right)^{1 / 2} \\
& \underline{h}_{t}=(b+B) A C E_{t-1}\left(\frac{v\left(1-\tau_{t}\right)}{\gamma}+\frac{1}{2}\right) z_{t} \\
& =(b+B) A C\left(\frac{v\left(1-\tau_{t}\right)}{\gamma}+\frac{1}{2}\right)\left(\left(\frac{\gamma}{2 v+\gamma}\right)\left(\frac{\tau_{t}}{1-\tau_{t}}\right)\right)^{1 / 2}\left(E_{t-1}^{2}-\frac{2 B h^{*} E_{t-1}}{(b+B) A C}+\frac{\theta_{t}\left(B h^{*}\right)^{2}}{\left(\theta_{t}(b+B)-1\right)(b+B)(A C)^{2}}\right)^{1 / 2}
\end{aligned}
$$

This leads to the following

Corollary. As the relative quality of teachers falls over time in the RDE (according to the Theorem), the absolute quality of teachers characterized by their human capital attainment grows: both the human capital of the top teacher and the least qualified one, $\bar{h}_{t}, \underline{h}_{t}$, increase over time. 
Discussion. The intuition for the above results is based on the facts characterizing economic growth in our model. The growth of per student quality of basic education increases the opportunity to pursue higher education for an expanding group of students. Namely, college attendance becomes worthwhile for an ever broader group of students, adding on students with relatively low ability. At the same time, the human capital attainment of higher ability students increases disproportionately relative to their less able peers due to non-linearity in the college education production function (7). In other words, economic growth drives the rise of income inequality within the group of college educated individuals. As a result, hiring high ability individuals as teachers becomes a relatively more expensive option, which pushes the qualityquantity trade-off in the education policy in favor of the latter. This argument is made explicit by the following result which characterizes the evolution of income inequality in our model.

Based on the income formulas (4)-(5), the human capital accumulation formulas (6)-(7) and using the uniform distribution of abilities, as well as the formula (9) for the threshold ability between the groups, we can obtain the mean income of unskilled individuals:

$$
\bar{I}_{t}^{u}=\frac{I_{t}^{u}\left(a_{t}^{*}\right)}{2}=\frac{w_{t} \theta_{t} B h^{*}}{2\left(\theta_{t}(b+B)-1\right)}=\frac{w_{t} C E_{t-1} a_{t}^{*}}{2}
$$

and the mean income of the skilled (ignoring the distortion due to collective bargaining in the education sector):

$$
\bar{I}_{t}^{s}=\frac{I_{t}^{s}\left(a_{t}^{*}\right)+I_{t}^{s}(A)}{2}=\frac{w_{t} \theta_{t}}{2}\left(\frac{(b+B) \theta_{t} B h^{*}}{\left(\theta_{t}(b+B)-1\right)}+A(b+B) C E_{t-1}-2 B h^{*}\right)
$$

Thus the inequality between the groups is given by

$$
\sigma_{t}^{s / u}=\frac{\bar{I}_{t}^{s}}{\bar{I}_{t}^{u}}=\frac{A(b+B) C E_{t-1}\left(\theta_{t}(b+B)-1\right)}{B h^{*}}+\left(2-\theta_{t}(b+B)\right)
$$

This expression obviously increases in basic education quality, which according to Lemma 1 rises over time.

The inequality within the skilled group (ignoring the aforementioned distortion) is characterized by

$$
\sigma_{t}^{s}=\frac{I_{t}^{s}(A)}{I_{t}^{s}\left(a_{t}^{*}\right)}=\frac{(b+B) A C E_{t-1}-B h^{*}}{(b+B) a_{t}^{*} C E_{t-1}-B h^{*}}=\left(\theta_{t}(b+B)-1\right) \frac{(b+B) A C E_{t-1}-B h^{*}}{B h^{*}}
$$


which also grows as basic education quality rises over time. One can rewrite this expression, according to (9), as

$$
\sigma_{t}^{s}=\frac{\theta_{t}(b+B)}{a_{t}^{*}}\left(A-\frac{B h^{*}}{C E_{t-1}}\right)
$$

This demonstrates that the upward trend of the absolute disparity between the highest and lowest incomes of skilled workers can be attributed to two factors: (i) the rise of basic education quality $E_{t-1}$ which increases human capital and therefore incomes of all workers, but disproportionately more so at the high end of ability distribution; (ii) falling, according to Lemma 2, college attendance ability cut-off which brings lower ability workers into the fold of the skilled hence increasing the intra-group inequality.

We summarize the above results as

Theorem 2 (The Evolution of Income Inequality). The recursive equilibrium dynamics exhibits growing inequality within the group of skilled individuals, as well the increase in inequality between this group and the unskilled.

As we discussed above and in Section 2, this result is due to the absolute growth of the quality of basic publicly provided education, which has unequal impact on individuals across the distribution of abilities because of the complementary relationship between individual ability and quality of education. ${ }^{7}$

The recent growth literature which presents evidence of rising dispersion of incomes of skilled workers over the last decades attributes this to the skill biased nature of technological change (see Acemoglu (1998), (2000) and Galor \& Moav (2000)). While our results have been derived from the impact of growing public provision of basic education without assuming a rise in skill premium $\theta_{t}$, one should expect the latter to exacerbate the effect.

\footnotetext{
${ }^{7}$ A somewhat similar argument for the magnifying effect that greater public education funding may have on income distribution is advanced by Glomm and Kaganovich (2003) in the presence of complementarity between public and parental private inputs, imperfect altruism and borrowing constraints. The fact of such complementary relationship and its implications for inequality was documented for the case of Britain by LeGrand (1982).
} 
We will now introduce exogenous skill biased technological change into the model given by positive shocks to the skill premium coefficients $\theta_{t}$ and will explore its effects on the education policy variables and the quality of education. Specifically, we consider the recursive dynamic equilibrium (RDE) corresponding to the original (benchmark) exogenously given sequence $\left\{\theta_{t}\right\}_{t=o}^{\infty}$ and assume that the productivity augmentation of skilled labor receives a positive shock from time $t_{0}$ on, i.e. that for $\mathrm{t}=\mathrm{t}_{0}, \mathrm{t}_{0}+1, \ldots$ the value $\theta_{t}$ is replaced with some $\theta_{t}^{\prime}>\theta_{t}$. We will characterize the effect of this exogenous change on the RDE, particularly on the education policy variables. We obtain the following comparative dynamics result (see Appendix for the proof).

Theorem 3 (The Effect of Skill Biased Technological Change). Consider the comparative dynamics experiment described above where skill premium coefficients $\theta_{t}$ receive a positive shock from period $t_{0}$ on. The corresponding recursive dynamic equilibrium, relative to the benchmark RDE for $t \geq t_{0}$, will be characterized by

- lower quantity of teachers $z_{t}$;

- lower aggregate quality of teachers $q_{t}$ and therefore

- lower quality of basic education $E_{t}$.

Note the negative effect on both the number and aggregate quality of teachers which is due to an upward shock to the cost of skilled labor. The theorem thus shows that the technological change biased toward skilled labor will have a detrimental effect on the absolute quality of basic education, exacerbating the negative effect of a secular downward trend in the relative quality of teachers stated in Theorem 1. These results will apply, in particular, when the education tax rate $\tau$ stays constant, which means that education budget remains a constant fraction of GDP, i.e. grows at the same rate. This leads to an important implication of our result that given the negative impact of rising skill premium on the quality of education, a policy aimed at neutralizing this effect would require an increase in funding of education (assuming no change in the institutional setup of the school system and teachers' labor market) at a rate faster than 
GDP growth, i.e. raising the fraction of GDP devoted to education. A proper interpretation of this conclusion follows directly from our results: the relative cost of maintaining a given teacher quality standard will rise over time.

\section{Conclusions}

Over the last forty years, education policy in the U.S. has changed significantly, focusing in particular on lowering the student-teacher ratio. We have developed a model which offers an insight into this evolution by relating it to the changes in the US economy characterized by rising skill premium and overall income inequality. We argue that teacher wage compression due in large part to collective bargaining agreements has a significant effect on decisions concerning quantity-quality trade-offs in hiring teachers. Our model predicts that as incomes rise and become more dispersed, education policy-makers are forced to adjust relative teacher salaries and thereby quality standards. Education quality is optimized by lowering relative quality of teachers while increasing their numbers. This causes the higher ability college educated people to choose private sector employment which offers higher reward to skilled workers.

We argue moreover that a rise in skill premium caused, in particular, by skill biased technological change will exacerbate the negative trends in the relative quality of education. Indeed, the labor of college graduates will further appreciate relative to the average wage and hence relative to the tax revenue. Countering this trend would therefore require an increase in the share of GDP spent on basic education, assuming that the institutional setup of the school system remains unchanged.

Our finding that skill biased technological change can have a negative effect on the quality of education is an interesting case of negative feedback, since SBTC literature points to the rise in the supply of skill due to growing availability of education as its underlying cause. Furthermore, this leads to an issue which appears important for future research on the aggregate long term effects of SBTC: as the technical change brings about productivity gains, one needs to factor in its effects on the cost and quality of education and the corresponding policy responses in order to assess the full long-term impact. 


\section{References}

Aaronson, D., L. Barrow, and W. Sander, 2007. "Teachers and Student Achievement in the Chicago Public High Schools," Journal of Labor Economics 25, 95-135.

Acemoglu, D., 1998. "Why Do New Technologies Complement Skills? Directed Technical Change and Wage Inequality," Quarterly Journal of Economics 113, 1055-1089.

Acemoglu, D., 2000. "Technical Change, Inequality, and the Labor Market," Journal of Economic Literature 40, 7-72.

Angrist, J. and V. Lavy, 1999. "Using Maimonides' Rule To Estimate The Effect Of Class Size On Scholastic Achievement.," Quarterly Journal of Economics 114, 533-575.

Bacolod, M., 2006. "Do Alternative Opportunities Matter? The Role of Female Labor Markets in the Decline of Teacher Quality," Working Paper 06-22, Center for Economic Studies, U.S. Census Bureau.

Ben-Porath, Y., 1967. "The Production of Human Capital and the Life-Cycle Earnings," Journal of Political Economy 75, 352-365.

Betts, J., 1998. "The Impact of Educational Standards on the Level and Distribution of Earnings," American Economic Review 88, 266-275.

Card, D. and A. Krueger, 1992. "Does School Quality Matter? Returns to Education and the Characteristics of Public Schools in the United States," Journal of Political Economy 100, 1-40.

Clotfelter, C., H. Ladd, and J. Vigdor, 2007. "How and Why Do Teacher Credentials Matter for Student Achievement?" NBER Working Paper No. W12828.

Corcoran, S., W. Evans, and R. Schwab, 2004. "Changing Labor-Market Opportunities for Women and the Quality of Teachers, 1957-2000," American Economic Review, 94, 230-235.

Cunha, F. and J. Heckman, 2007. "The Technology of Skill Formation," American Economic Review 97, 31-47.

Eckstein, Z. and I. Zilcha, 1994. "The Effects of Compulsory Schooling on Growth, Income 
Distribution and Welfare," Journal of Public Economics 54, 339-359.

Flyer, F. and S. Rosen, 1997. "The New Economics of Teachers and Education," Journal of Labor Economics 15, S104-S139.

Galor, O. and O. Moav, 2000. "Ability-Biased Technological Transition, Wage Inequality, and Economic Growth," Quarterly Journal of Economics 115, 469-497.

Glomm, G. and M. Kaganovich, 2003. "Distributional Effects of Public Education in an Economy with Public Pensions," International Economic Review 44, 917-937.

Glomm, G. and B. Ravikumar, 1992. "Public versus Private Investment in Human Capital: Endogenous Growth and Income Inequality,” Journal of Political Economy 100, 818-834.

Goldhaber, D. and E. Anthony, 2007. "Can Teacher Quality Be Effectively Assessed? National Board Certification As a Signal of Effective Teaching," Review of Economics and Statistics 89, 134-150.

Goldhaber, D. and A. Liu, 2003. "Occupational Choices and the Academic Proficiency of the Teacher Workforce," In: W. Fowler (ed.), Developments in School Finance 2001-02. NCES, Washington, DC, pp. 53-75.

Hanushek, E., 1999. "Some Findings from an Independent Investigation of the Tennessee STAR Experiment and from Other Investigations of Class Size Effects," Educational Evaluation and Policy Analysis, 21, 143-163.

Hanushek, E. and S. Rivkin, 1997. "Understanding the 20th Century Growth in U.S. School Spending," Journal of Human Resources 32, 35-68.

Hanushek, E. and S. Rivkin, 2003. "How to Improve the Supply of High-Quality Teachers," Brookings Papers on Education Policy, 7-25.

Hanushek, E., J. Kain, D. O'Brien, and S. Rivkin., 2005. "The Market for Teacher Quality," NBER Working Paper 11154.

Hatsor, L., 2008. "The Allocation of Public Education Resources.” Tel Aviv University, Foerder Working Papers, 1-08. 
Hoxby, C. and A. Leigh, 2004. "Pulled Away or Pushed Out? Explaining the Decline of Teacher Aptitude in the United States," American Economic Review 94, 236-240.

Hoxby, C., 1996. "How Teachers' Unions Affect Education Production," Quarterly Journal of Economics 111, 671-718.

Huggett, M., G. Ventura, and A. Yaron, 2006. "Human Capital and Earnings Distribution Dynamics," Journal of Monetary Economics 53, 265-290.

Jepsen, C. and S. Rivkin, 2002. "What is the Tradeoff Between Smaller Classes and Teacher Quality?" NBER Working Paper No. W9205.

Krueger, A., 1999. "Experimental Estimates of Education Production Functions," Quarterly Journal of Economics 114, 497-532.

Krueger, A. and D. Whitmore, 2001. "The Effect of Attending a Small Class in the Early Grades on College-Test Taking and Middle School Test Results: Evidence from Project STAR," Economic Journal 111, 1-28.

Lakdawalla, D., 2006. "The Economics of Teacher Quality," Journal of Law and Economics 49, 285-329.

LeGrand, J., 1982. The Strategy of Equality Redistribution and the Social Services. London: George Allen and Unwin.

Restuccia, D. and C. Urrutia, 2004. "Intergenerational Persistence of Earnings: the Role of Early and College Education," American Economic Review 94, 1354-1378.

Rivkin, S., E. Hanushek, and J. Kain, 2005. "Teachers, Schools and Academic Achievement," Econometrica 73, 417-458.

Rosen, S., "A Theory of Life Earnings," Journal of Political Economy 84, S45-S67.

Su, X., 2004. "The Allocation of Public Funds in a Hierarchical Educational System," Journal of Economic Dynamics and Control 28, 2485-2510.

Tamura, R., 2001. "Teachers, Growth, and Convergence," Journal of Political Economy 109, 
1021-1059. 


\section{Appendix 1}

We will first prove Lemmas 1 and 2 under the hypothesis that Lemma 3 is correct. We will then prove that Lemma 3 is indeed correct in the recursive dynamic equilibrium, and thereby the imposition of the hypothesis will not have diminished the generality of (or create circularity problems with) the argument.

\section{Proof of Lemma 1.}

Recall that according to (20) $E_{t}=\left(z_{t}(b+B) C E_{t-1} \bar{a}_{t}-z_{t} B h^{*}-\frac{1}{2}(b+B) A C E_{t-1} z_{t}^{2}\right)^{v} z_{t}^{\gamma}$.

Substituting

the expression for $\bar{a}_{t}$ given in (34), we obtain $E_{t}=\left(A(b+B) C E_{t-1}\left(\frac{v\left(1-\tau_{t}\right)}{\gamma}\right)\right)^{v} z_{t}^{2 v+\gamma}$, or according to (33)

$E_{t}=\left(\frac{A(b+B) C E_{t-1} v\left(1-\tau_{t}\right)}{\gamma}\right)^{v}\left(\left(\frac{\gamma}{2 v+\gamma}\right)\left(\frac{\tau_{t}}{1-\tau_{t}}\right)\left(1-\frac{2 B h^{*}}{(b+B) A C E_{t-1}}+\frac{\theta_{t}\left(B h^{*}\right)^{2}}{\left(\theta_{t}(b+B)-1\right)(b+B)\left(A C E_{t-1}\right)^{2}}\right)\right)^{v+\gamma / 2}$

Note that since $\frac{\theta_{t}(b+B)}{\theta_{t}(b+B)-1}>1$, the following inequality is true

$$
1-\frac{2 B h^{*}}{(b+B) A C E_{t-1}}+\frac{\theta_{t}\left(B h^{*}\right)^{2}}{(b+B)\left(\theta_{t}(b+B)-1\right)\left(A C E_{t-1}\right)^{2}}>\left[1-\frac{B h^{*}}{(b+B) A C E_{t-1}}\right]^{2}
$$

Therefore we can write

$$
E_{t}>\left(\frac{v}{\gamma}(b+B) A C E_{t-1}\left(1-\tau_{t}\right)\right)^{v}\left(\left(\frac{\gamma}{2 \nu+\gamma}\right)\left(\frac{\tau_{t}}{1-\tau_{t}}\right)\right)^{\nu+\gamma / 2}\left(1-\frac{B h^{*}}{(b+B) A C E_{t-1}}\right)^{2 v+\gamma}
$$

Thus, in order to prove the Lemma it is sufficient to show that for all $t=0,1, \ldots$

$$
\left(\frac{v}{\gamma}(b+B) A C\left(1-\tau_{t}\right)\right)^{\frac{1}{2+\gamma / v}}\left(\left(\frac{\gamma}{2 v+\gamma}\right)\left(\frac{\tau_{t}}{1-\tau_{t}}\right)\right)^{\frac{1+\gamma / 2 v}{2+\gamma / v}}\left(1-\frac{B h^{*}}{(b+B) A C E_{t-1}}\right)>1
$$

which is indeed true according to Assumption 1 and by the induction argument. 


\section{Proof of Lemma 2.}

Based on Lemma 3 we use expression (9) for $a_{t}^{*}$. Then according to (35) our task of proving the inequality $\underline{a}_{t}>a_{t}^{*}$. is equivalent to verifying the inequality

$$
\frac{B h^{*}}{(b+B) C E_{t-1}}+A z_{t}\left(\frac{v\left(1-\tau_{t}\right)}{\gamma}-\frac{1}{2}\right)>\frac{1}{C E_{t-1}} \frac{\theta_{t} B h^{*}}{\theta_{t}(b+B)-1} \text { or } A z_{t}\left(\frac{v\left(1-\tau_{t}\right)}{\gamma}-\frac{1}{2}\right)>\frac{1}{(b+B) C E_{t-1}} \frac{B h^{*}}{\theta_{t}(b+B)-1}
$$

Upon substituting the expression (33) for $z_{t}$, the last inequality becomes

$$
\begin{aligned}
& A\left(\frac{v\left(1-\tau_{t}\right)}{\gamma}-\frac{1}{2}\right)\left(\left(\frac{\gamma}{2 v+\gamma}\right)\left(\frac{\tau_{t}}{1-\tau_{t}}\right)\right)^{1 / 2}\left(1-\frac{2 B h^{*}}{(b+B) A C E_{t-1}}+\frac{\theta_{t}\left(B h^{*}\right)^{2}}{\left(\theta_{t}(b+B)-1\right)(b+B)\left(A C E_{t-1}\right)^{2}}\right)^{1 / 2} \\
& >\frac{1}{(b+B) C E_{t-1}} \frac{B h^{*}}{\theta_{t}(b+B)-1}
\end{aligned}
$$

Under Lemma 3 the right hand side in (42) is less than $\frac{A}{\theta_{t}(b+B)}$ since $a_{t}^{*}<A$.. Therefore according to (41) in order to prove inequality (42) it is by far sufficient to establish

$$
\left(\frac{v\left(1-\tau_{t}\right)}{\gamma}-\frac{1}{2}\right)\left(\left(\frac{\gamma}{2 \nu+\gamma}\right)\left(\frac{\tau_{t}}{1-\tau_{t}}\right)\right)^{1 / 2}\left(1-\frac{B h^{*}}{(b+B) A C E_{t-1}}\right)>\frac{1}{\theta_{t}(b+B)}
$$

which is indeed true for all $t=0,1, \ldots$ according to Assumption 2 combined with Lemma 1 .

\section{Proof of Lemma 3.}

The above proofs were based on the hypothesis that Lemma 3 is correct, i.e. that the ability cutoff for college attendance $a_{t}^{*}$ satisfies equality (9), i.e. we proved that if college attendance cutoff ability is $a_{t}^{*}=\frac{1}{C E_{t-1}} \frac{\theta_{t} B h^{*}}{\theta_{t}(b+B)-1}$ then the optimal education policy requires that all teachers' ability strictly exceed this threshold.. This in turn means that the marginal college graduate will be employed in the production sector. As we explained after stating equality (9), if an individual with ability below attended college his skilled human capital given adjusted for the net productivity augmentation $\theta_{t}$ will be inferior to his unskilled human capital derived from the first stage of education, therefore a job in production sector's skilled labor force would not compel such individual to attend college. Thus the only way the violation of Lemma 3 could occur is if such individual had an opportunity to be hired as a teacher. Compare, however, 
optimization problem (20) where $a_{t}^{*}<\frac{1}{C E_{t-1}} \frac{\theta_{t} B h^{*}}{\theta_{t}(b+B)-1} \quad$ versus the one where $a_{t}^{*}=\frac{1}{C E_{t-1}} \frac{\theta_{t} B h^{*}}{\theta_{t}(b+B)-1}$. One can easily see that the only difference would be a lower tax revenue $T_{t}$ in the former case. Therefore such government policy would be inferior to the one where $a_{t}^{*}=\frac{1}{C E_{t-1}} \frac{\theta_{t} B h^{*}}{\theta_{t}(b+B)-1}$. Thus the latter indeed characterizes the recursive dynamic equilibrium optimum, i.e. Lemma 3 is correct.

\section{Proof of inequality (41)}

We rewrite the inequality by squaring its both sides:

$$
\left(\left(\frac{\gamma}{2 v+\gamma}\right)\left(\frac{\tau_{t}}{1-\tau_{t}}\right)\right)>\left(\frac{\gamma}{2 v+\gamma}\right)^{2}\left(\frac{\tau_{t}}{1-\tau_{t}}\right)^{2}\left(\frac{2 v\left(1-\tau_{t}\right)+\gamma}{2 \gamma}\right)^{2}
$$

which can be simplified: $\left(1-\tau_{t}\right)\left(2 \frac{v}{\gamma}+1\right)>\tau_{t}\left(\frac{v}{\gamma}\left(1-\tau_{t}\right)+\frac{1}{2}\right)^{2}$. This last inequality is certainly true if $\left(1-\tau_{t}\right)\left(2 \frac{v}{\gamma}+1\right)>\tau_{t}\left(\frac{v}{\gamma}+\frac{1}{2}\right)^{2}$ which reduces to $\tau_{t}<\frac{4}{5+2 v / \gamma}$.

\section{Proof of Theorem 3.}

The proof will proceed by induction argument.

Consider firstly the effect of a positive shock to coefficient $\theta_{t}$ in period $\mathrm{t}=\mathrm{t}_{0}$ on education policy variables in this same period. According to (33) direct derivative $\frac{\partial z_{t}}{\partial \theta_{t}}$ has the same sign as $\frac{\partial}{\partial \theta_{t}}\left[\frac{\theta_{t}}{\theta_{t}(b+B)-1}\right]$, i.e. negative, so we can write

$$
\frac{\partial z_{t}}{\partial \theta_{t}}<0
$$

Therefore, according to (34) and (35), respectively, we can write 


$$
\begin{aligned}
& \frac{\partial \bar{a}_{t}}{\partial \theta_{t}}=\frac{\partial \bar{a}_{t}}{\partial z_{t}} \frac{\partial z_{t}}{\partial \theta_{t}}=A\left(1.5-\tau_{t}\right) \frac{\partial z_{t}}{\partial \theta_{t}}<0 \\
& \frac{\partial \underline{a}_{t}}{\partial \theta_{t}}=\frac{\partial \underline{a}_{t}}{\partial z_{t}} \frac{\partial z_{t}}{\partial \theta_{t}}=A\left(0.5-\tau_{t}\right) \frac{\partial z_{t}}{\partial \theta_{t}}<0
\end{aligned}
$$

Recall that according to the derivation of (20)

$$
q_{t}=\left[(b+B) C E_{t-1} \bar{a}_{t}-B h^{*}-\frac{1}{2} z_{t} A(b+B) C E_{t-1}\right] z_{t}
$$

since we have assumed $a=0$. Using formula (34) we can rewrite the above as

$$
q_{t}=A(b+B) C E_{t-1} \frac{v\left(1-\tau_{t}\right)}{\gamma} z_{t}^{2}
$$

which implies, according to (43) that

$$
\frac{\partial q_{t}}{\partial \theta_{t}}<0
$$

for $\mathrm{t}=\mathrm{t}_{0}$. Combining (43) and (46) and referring to (10) we can conclude that for $\mathrm{t}=\mathrm{t}_{0}$

$$
\frac{\partial E_{t}}{\partial \theta_{t}}<0
$$

We can now proceed to the next step of the induction and evaluate the effect born by the education policy variables in period $\mathrm{t}=\mathrm{t}_{0}+1$, keeping in mind two sources of this effect: the direct effect of higher value of $\theta_{t_{0}+1}$ and the indirect one caused by lower education quality in the previous period $E_{t_{0}}$ as established in (48). The results in (43), (47) and (48) show that the direct effects on the variables $z_{t+1}, q_{t+1}, E_{t+1}$ in any period $\mathrm{t}+1$ of a contemporaneous rise in $\theta_{t+1}$ are negative. For the purposes of completing the induction argument it will therefore be sufficient to prove that a decline in $E_{t}$ will have a negative effect on $z_{t+1}, q_{t+1}, E_{t+1}$, in other words that the derivatives of these variables with respect to $E_{t}$ are all positive. 
According to (33) the derivative $\frac{\partial\left(z_{t+1}^{2}\right)}{\partial E_{t}}$ has the same sign as the expression $1-\frac{\theta_{t+1} B h^{*}}{\left(\theta_{t+1}(b+B)-1\right) A C E_{t-1}}$, which according to Lemma 3 is equal to $1-A^{-1} a_{t}^{*}$ and therefore is positive. Thus we can conclude that

$$
\frac{\partial z_{t+1}}{\partial E_{t}}>0
$$

Rewriting expression (46) for period $\mathrm{t}+1: \quad q_{t+1}=A(b+B) C E_{t} \frac{v\left(1-\tau_{t+1}\right)}{\gamma} z_{t+1}^{2}$, we note that a rise in $E_{t}$ affects $q_{t+1}$ directly (obviously positively) as well as through $z_{t+1}$, i.e. also positively according (49). Thus we can conclude that $\frac{\partial q_{t+1}}{\partial E_{t}}>0$. This combined with (49) implies due to (10) that $\frac{\partial E_{t+1}}{\partial E_{t}}>0$. Thus according to the above discussion the theorem's proof is complete. 


\section{Appendix 2}

Glossary of Mathematical Terms

$\begin{array}{ll}\beta & \text { Discount factor in individual intertemporal preferences } \\ \tau_{t} & \text { Labor income tax rate in period } \mathrm{t} \\ T_{t} & \text { Total government revenue in period } \mathrm{t} \\ a & \text { Lower bound on innate ability, from Section } 4 \text { on } a=0 \text { is assumed } \\ A & \text { Upper bound on innate ability } \\ a(\omega) & \text { The innate ability of individual } \omega \\ a_{t}^{*} & \text { Ability cut-off level for attending college in period } \mathrm{t} \\ h_{t}^{u}(\omega) & \text { Unskilled individual's level of human capital in period } \mathrm{t} \\ H_{t}^{u} & \text { Aggregate unskilled human capital in goods production in period } \mathrm{t} \\ h_{t}^{s}(\omega) & \text { Skilled individual's level of human capital in period } \mathrm{t} \\ H_{t}^{s} & \text { Aggregate skilled human capital in period } \mathrm{t} \\ H_{t}^{s y} & \text { Aggregate skilled human capital in goods production in period } \mathrm{t} \\ C & \text { Productivity coefficient of compulsory basic education } \\ E_{t} & \text { Public education quality in period } \mathrm{t} \\ b & \text { Coefficient of in-college depreciation of pre-college human capital. } \\ B & \text { Productivity coefficient of higher education } \\ h^{*} & \text { Human capital threshold for admission to college } \\ D & \text { TFP coefficient in the goods production sector } \\ \alpha & \text { Physical capital income share in the goods production sector } \\ \theta_{t} & \text { Productivity augmentation of skilled human capital (skill premium) in } \\ \gamma & \text { the production sector in period } \mathrm{t} \\ v & \text { Returns to quantity of teachers } \\ \Sigma_{t} & \text { Returns to quality of teachers } \\ z_{t} & \text { Set of individuals employed as teachers in period } \mathrm{t} \\ I_{t}^{h} & \text { Number of teachers (the share of teachers in the working population) in } \\ a_{t} & \text { period } \mathrm{t} \\ h_{t} & \text { Teacher's salary in period } \mathrm{t} \\ \bar{a}_{t} & \text { The lowest ability level among teachers in period } \mathrm{t} \\ \bar{h}_{t} & \text { The lowest human capital level among teachers in period } \mathrm{t} \\ q_{t} & \text { The highest ability level among teachers in period } \mathrm{t} \\ & \text { Ahe highest human capital level among teachers in period } \mathrm{t} \\ & \text { Aggregate teacher quality in period } \mathrm{t} \\ & \end{array}$




\section{CESifo Working Paper Series}

for full list see www.cesifo-group.org/wp

(address: Poschingerstr. 5, 81679 Munich, Germany, office@cesifo.de)

2453 Bernd Theilen, Market Competition and Lower Tier Incentives, November 2008

2454 Ondřej Schneider, Voting in the European Union - Central Europe's Lost Voice, November 2008

2455 Oliver Lorz and Gerald Willmann, Enlargement versus Deepening: The Trade-off Facing Economic Unions, November 2008

2456 Alfons J. Weichenrieder and Helen Windischbauer, Thin-Capitalization Rules and Company Responses, Experience from German Legislation, November 2008

2457 Andreas Knabe and Steffen Rätzel, Scarring or Scaring? The Psychological Impact of Past Unemployment and Future Unemployment Risk, November 2008

2458 John Whalley and Sean Walsh, Bringing the Copenhagen Global Climate Change Negotiations to Conclusion, November 2008

2459 Daniel Mejía, The War on Illegal Drugs in Producer and Consumer Countries: A Simple Analytical Framework, November 2008

2460 Carola Frydman, Learning from the Past: Trends in Executive Compensation over the Twentieth Century, November 2008

2461 Wolfgang Ochel, The Political Economy of Two-tier Reforms of Employment Protection in Europe, November 2008

2462 Peter Egger and Doina Maria Radulescu, The Influence of Labor Taxes on the Migration of Skilled Workers, November 2008

2463 Oliver Falck, Stephan Heblich and Stefan Kipar, The Extension of Clusters: Differencein-Differences Evidence from the Bavarian State-Wide Cluster Policy, November 2008

2464 Lei Yang and Keith E. Maskus, Intellectual Property Rights, Technology Transfer and Exports in Developing Countries, November 2008

2465 Claudia M. Buch, The Great Risk Shift? Income Volatility in an International Perspective, November 2008

2466 Walter H. Fisher and Ben J. Heijdra, Growth and the Ageing Joneses, November 2008

2467 Louis Eeckhoudt, Harris Schlesinger and Ilia Tsetlin, Apportioning of Risks via Stochastic Dominance, November 2008

2468 Elin Halvorsen and Thor O. Thoresen, Parents' Desire to Make Equal Inter Vivos Transfers, November 2008 
2469 Anna Montén and Marcel Thum, Ageing Municipalities, Gerontocracy and Fiscal Competition, November 2008

2470 Volker Meier and Matthias Wrede, Reducing the Excess Burden of Subsidizing the Stork: Joint Taxation, Individual Taxation, and Family Splitting, November 2008

2471 Gunther Schnabl and Christina Ziegler, Exchange Rate Regime and Wage Determination in Central and Eastern Europe, November 2008

2472 Kjell Erik Lommerud and Odd Rune Straume, Employment Protection versus Flexicurity: On Technology Adoption in Unionised Firms, November 2008

2473 Lukas Menkhoff, High-Frequency Analysis of Foreign Exchange Interventions: What do we learn?, November 2008

2474 Steven Poelhekke and Frederick van der Ploeg, Growth, Foreign Direct Investment and Urban Concentrations: Unbundling Spatial Lags, November 2008

2475 Helge Berger and Volker Nitsch, Gotcha! A Profile of Smuggling in International Trade, November 2008

2476 Robert Dur and Joeri Sol, Social Interaction, Co-Worker Altruism, and Incentives, November 2008

2477 Gaëtan Nicodème, Corporate Income Tax and Economic Distortions, November 2008

2478 Martin Jacob, Rainer Niemann and Martin Weiss, The Rich Demystified - A Reply to Bach, Corneo, and Steiner (2008), November 2008

2479 Scott Alan Carson, Demographic, Residential, and Socioeconomic Effects on the Distribution of $19^{\text {th }}$ Century African-American Stature, November 2008

2480 Burkhard Heer and Andreas Irmen, Population, Pensions, and Endogenous Economic Growth, November 2008

2481 Thomas Aronsson and Erkki Koskela, Optimal Redistributive Taxation and Provision of Public Input Goods in an Economy with Outsourcing and Unemployment, December 2008

2482 Stanley L. Winer, George Tridimas and Walter Hettich, Social Welfare and Coercion in Public Finance, December 2008

2483 Bruno S. Frey and Benno Torgler, Politicians: Be Killed or Survive, December 2008

2484 Thiess Buettner, Nadine Riedel and Marco Runkel, Strategic Consolidation under Formula Apportionment, December 2008

2485 Irani Arraiz, David M. Drukker, Harry H. Kelejian and Ingmar R. Prucha, A Spatial Cliff-Ord-type Model with Heteroskedastic Innovations: Small and Large Sample Results, December 2008 
2486 Oliver Falck, Michael Fritsch and Stephan Heblich, The Apple doesn't Fall far from the Tree: Location of Start-Ups Relative to Incumbents, December 2008

2487 Cary Deck and Harris Schlesinger, Exploring Higher-Order Risk Effects, December 2008

2488 Michael Kaganovich and Volker Meier, Social Security Systems, Human Capital, and Growth in a Small Open Economy, December 2008

2489 Mikael Elinder, Henrik Jordahl and Panu Poutvaara, Selfish and Prospective: Theory and Evidence of Pocketbook Voting, December 2008

2490 Maarten Bosker and Harry Garretsen, Economic Geography and Economic Development in Sub-Saharan Africa, December 2008

2491 Urs Fischbacher and Simon Gächter, Social Preferences, Beliefs, and the Dynamics of Free Riding in Public Good Experiments, December 2008

2492 Michael Hoel, Bush Meets Hotelling: Effects of Improved Renewable Energy Technology on Greenhouse Gas Emissions, December 2008

2493 Christian Bruns and Oliver Himmler, It's the Media, Stupid - How Media Activity Shapes Public Spending, December 2008

2494 Andreas Knabe and Ronnie Schöb, Minimum Wages and their Alternatives: A Critical Assessment, December 2008

2495 Sascha O. Becker, Peter H. Egger, Maximilian von Ehrlich and Robert Fenge, Going NUTS: The Effect of EU Structural Funds on Regional Performance, December 2008

2496 Robert Dur, Gift Exchange in the Workplace: Money or Attention?, December 2008

2497 Scott Alan Carson, Nineteenth Century Black and White US Statures: The Primary Sources of Vitamin D and their Relationship with Height, December 2008

2498 Thomas Crossley and Mario Jametti, Pension Benefit Insurance and Pension Plan Portfolio Choice, December 2008

2499 Sebastian Hauptmeier, Ferdinand Mittermaier and Johannes Rincke Fiscal Competition over Taxes and Public Inputs: Theory and Evidence, December 2008

2500 Dirk Niepelt, Debt Maturity without Commitment, December 2008

2501 Andrew Clark, Andreas Knabe and Steffen Rätzel, Boon or Bane? Others' Unemployment, Well-being and Job Insecurity, December 2008

2502 Lukas Menkhoff, Rafael R. Rebitzky and Michael Schröder, Heterogeneity in Exchange Rate Expectations: Evidence on the Chartist-Fundamentalist Approach, December 2008 
2503 Salvador Barrios, Harry Huizinga, Luc Laeven and Gaëtan Nicodème, International Taxation and Multinational Firm Location Decisions, December 2008

2504 Andreas Irmen, Cross-Country Income Differences and Technology Diffusion in a Competitive World, December 2008

2505 Wenan Fei, Claude Fluet and Harris Schlesinger, Uncertain Bequest Needs and LongTerm Insurance Contracts, December 2008

2506 Wido Geis, Silke Uebelmesser and Martin Werding, How do Migrants Choose their Destination Country? An Analysis of Institutional Determinants, December 2008

2507 Hiroyuki Kasahara and Katsumi Shimotsu, Sequential Estimation of Structural Models with a Fixed Point Constraint, December 2008

2508 Barbara Hofmann, Work Incentives? Ex Post Effects of Unemployment Insurance Sanctions - Evidence from West Germany, December 2008

2509 Louis Hotte and Stanley L. Winer, The Demands for Environmental Regulation and for Trade in the Presence of Private Mitigation, December 2008

2510 Konstantinos Angelopoulos, Jim Malley and Apostolis Philippopoulos, Welfare Implications of Public Education Spending Rules, December 2008

2511 Robert Orlowski and Regina T. Riphahn, The East German Wage Structure after Transition, December 2008

2512 Michel Beine, Frédéric Docquier and Maurice Schiff, International Migration, Transfers of Norms and Home Country Fertility, December 2008

2513 Dirk Schindler and Benjamin Weigert, Educational and Wage Risk: Social Insurance vs. Quality of Education, December 2008

2514 Bernd Hayo and Stefan Voigt, The Relevance of Judicial Procedure for Economic Growth, December 2008

2515 Bruno S. Frey and Susanne Neckermann, Awards in Economics - Towards a New Field of Inquiry, January 2009

2516 Gregory Gilpin and Michael Kaganovich, The Quantity and Quality of Teachers: A Dynamic Trade-off, January 2009 